\title{
Simulation of Lead lons Adsorption onto the Iron-Coated Medium: Dependent on Temperature and $\mathrm{pH}$
}

\author{
C. H. Lai'; C. K. Gao²; T. T. Lin ${ }^{3}$; S. H. Yeh"; C. Y. Chen ${ }^{5}$; and M. K. Wang ${ }^{6}$
}

\begin{abstract}
Heat was employed to coat crystalline goethite onto a quartz sand surface so that the adsorbent properties of the coating could be utilized. Adsorption experiments were conducted to further demonstrate the adsorption of lead ions by goethite-coated medium under various temperatures and $\mathrm{pH}$, respectively. The adsorption reaction between iron-coated medium and lead ions was simulated by a cation exchange model. Results indicated that the solution temperature and $\mathrm{pH}$ had a noticeable effect on the final adsorption capacity for lead ions. The $\mathrm{pH}$-adsorption edges were shifted to lower $\mathrm{pH}$ values with increasing temperature. The adsorption reaction between lead ions and goethite-coated medium was an endothermic process. A cation exchange model applied to the regression model of experimental data was fitted very well. A high correlation coefficient $\left(r^{2}=0.91\right)$ and an extreme low $p$-value $\left(7.02 \times 10^{-82}\right)$ indicated that the variance of dependent variable, adsorption capacity of iron-coated medium could be firmly explained by independent variables such as $\left[\mathrm{Pb}^{+n}\right]$, temperature and $\left[\mathrm{H}^{+}\right]$.
\end{abstract}

DOI: 10.1061/(ASCE)1090-025X(2006)10:1(28)

CE Database subject headings: Adsorption; Coating; Lead; Iron; Temperature; Simulation.

\section{Introduction}

Lead is a widely used metal in daily life. Concentrations of lead over the permissible level, in natural water or drinking water, may cause severe public health problems. The primary sources of lead include metal plating, industrial discharge, and mining wastes. Concentrations above the threshold value in drinking water produces various types of acute and chronic disorders (Singh et al. 1998).

Conventional methods for treating metal-bearing water that contains lead ions, follow alkaline precipitation. Adsorption processes for the high-level treatment of metal-bearing tap or wastewater are becoming increasingly attractive as drinking water or effluent concentration limits for metals are tightened. Moreover, traditional drinking water treatment (involving coagulation/ flocculation, sedimentation, and filtration) generally cannot com-

\footnotetext{
${ }^{1}$ Professor, Dept. of Environmental Engineering and Science, Fooyin Univ., Kaohsiung 831, Taiwan, Republic of China (corresponding author). E-mail: chlai@mail.fy.edu.tw

${ }^{2}$ Associate Professor, Dept. of Environmental Engineering and Science, Fooyin Univ., Kaohsiung 831, Taiwan, Republic of China.

${ }^{3}$ Associate Professor, Dept. of Civil Engineering, National Kaohsiung Univ. of Applied Science, Kaohsiung 807, Taiwan, Republic of China.

${ }^{4}$ Lecturer, Dept. of Healthcare Administration, Fooyin Univ., Kaohsiung 831, Taiwan, Republic of China.

${ }^{5}$ Associate Professor, Dept. of Environmental Engineering and Science, Fooyin Univ., Kaohsiung 831, Taiwan, Republic of China.

${ }^{6}$ Professor, Dept. of Agricultural Chemistry, National Taiwan Univ., Taipei 106, Taiwan, Republic of China.

Note. Discussion open until June 1, 2006. Separate discussions must be submitted for individual papers. To extend the closing date by one month, a written request must be filed with the ASCE Managing Editor. The manuscript for this paper was submitted for review and possible publication on July 25, 2005; approved on July 25, 2005. This paper is part of the Practice Periodical of Hazardous, Toxic, and Radioactive Waste Management, Vol. 10, No. 1, January 1, 2006. CASCE, ISSN 1090-025X/2006/1-28-32/\$25.00.
}

pletely remove trace metals (Lai et al. 2002). Adsorption can remove metals over a wider range of $\mathrm{pH}$ values and at lower concentrations than can alkaline precipitation. Iron oxides have a relatively high surface area and surface charge, and they often regulate free metal concentrations in water by adsorption. Many researchers have used iron oxide to remove heavy metals from tap or wastewater (Baes et al. 1997; Benjamin and Leckie 1981; Singh et al. 1993, 1998). However, most iron oxides are available only as fine powders or are generated in aqueous suspensions as hydroxide floc or gel. In such forms, these oxides can retain their desirable adsorptive properties for the trace metals but are limited to reactor configurations that involve incorporating large sedimentation basins or filtration unit. Under such conditions, solid/ liquid separation is quite difficult.

Recently, some researchers have presented techniques for coating iron oxide onto sand surfaces to overcome the above difficulties of using iron oxide powders in water treatment (Edwards and Benjamin 1989; Benjamin et al., 1996; Joshi and Chaudhuri 1996; Lai et al. 2000a,b; Lai and Chen 2001). The iron-coated sand has been tested for removal of cationic as well as anionic metals from synthetic and real wastes.

Synthetic iron oxides can be prepared from the hydrolysis of $\mathrm{Fe}^{3+}$ salt solutions under specific laboratory conditions. The major phases of iron oxide include ferrihydrite (poor crystalline iron oxide), goethite, and hematite during the heating procedure. The various crystalline iron oxides showed different chemical properties. McKenzie (1980) and Schwertmann and Taylor (1989) reported that heavy metals are adsorbed in the order of $\mathrm{Cu}>\mathrm{Pb}$ $>\mathrm{Zn}>\mathrm{Cd}$ by goethite, and $\mathrm{Pb}>\mathrm{Cu}>\mathrm{Zn}>\mathrm{Cd}$ by hematite. However, little work was conducted to coat the pure crystalline iron oxide onto the sand surface and investigated its adsorptive characteristics (Lai and Chen 2001; Lai et al. 2002). Additionally, one parameter that has received less attention is water temperature (Baker and Khalili 2004; Martins et al. 2004; Sharma, 2001). This is somewhat surprising since seasonal or even daily variations up to $20-40 \mathrm{~K}$ can occur in water systems, depending on parameters such as climate. 
Accordingly, this work utilized heat to coat crystalline goethite onto the surface of sand. Adsorption experiments were conducted to further demonstrate the adsorption of lead ions by goethitecoated medium under various solution temperature and $\mathrm{pH}$. Moreover, the adsorption reaction between goethite-coated medium and lead ions was simulated by a cation exchange model. This study can provide advanced information of adsorptive characteristics for iron-coated medium under various environments.

\section{Materials and Methods}

\section{Iron-Coated Medium Preparation}

Iron-coated medium was prepared following a procedure similar to that of Lai et al. (2002). The mineralogy of the quartz sand and iron oxide was determined by x-ray diffraction (X-ray Diffraction Meter, Tokyo Shibaura Model ADG-301E, Tokyo, Japan). The data published by the Joint Committee on Powder Diffraction Standards (JCPDS) were used to identify the crystalline phases. The sand turned out to be exclusively quartz (JCPDS pattern number: 33-1161). Iron oxide prepared by the coating procedure was verified to be the crystalline goethite (JCPDS pattern number: 29-713). The amount of iron on the goethite-coated medium surface, measured by acid digestion analysis, was approximately $5.8 \pm 0.2 \mathrm{mg} \mathrm{Fe} / \mathrm{g}$ sand.

\section{Adsorption Experiments}

All adsorption experiments were carried out in $125 \mathrm{~mL}$ Pyrex, Corning, U.S.A. vessels with agitation by a shaker. Vessels and all glassware were thoroughly washed with acid and rinsed with distilled water. Stock solutions of $0.01 \mathrm{M} \mathrm{Pb}(\mathrm{II})$ was prepared by dissolving appropriate amounts of $\mathrm{Pb}\left(\mathrm{NO}_{3}\right)_{2}$ in Milli-Q water. The experiment was conducted with a $50 \mathrm{~mL}$ solution containing a fixed concentration of lead, and $2.5 \mathrm{~g}$ goethite-coated medium was added. The solution $\mathrm{pH}$ was adjusted to a desired value with $0.1 \mathrm{M}, 0.01 \mathrm{M} \mathrm{HNO}_{3}$ and/or $\mathrm{NaOH}$. All chemicals used in the experiments were of analytical reagent grade (Merck Company, Germany). The temperature of the adsorption experiment was controlled by a water bath. The solution $\mathrm{pH}$ and temperature were controlled and ranged from 2.5 to 7.5 and from 283 to $333 \mathrm{~K}$, respectively. After $4 \mathrm{~h}$ of reaction, solid and liquid were separated using a $0.2 \mu \mathrm{m}$ membrane filter. The residual concentration of lead was determined by atomic absorption spectrophotometry (Perkin-Elmer A310).

\section{Adsorptive Characteristics Analyses}

Scanning electronic microscopy/energy dispersive x-ray (EDAX) analysis was employed to survey the adsorptive characteristics for lead ions on the goethite-coated medium. Samples for EDAX (Hitachi-S-2400, EDAX KEVEX Level 4, Japan) analysis were eluted several times with Milli-Q water for the sake of ensuring that electric conductivity of supernatant of sample approximately equal to that of the Milli-Q water. Freeze drying was used for drying the solid sand. Then, the goethite-coated medium was coated with thin carbon film in order to avoid the influence of charge effect during the EDAX operation. Elemental microprobe technique was used for analyzing the elemental constitution of solid samples. The scanning energy for EDAX analysis was from 0 to $10.23 \mathrm{keV}$ with an elapsed time of $100 \mathrm{~s}$.

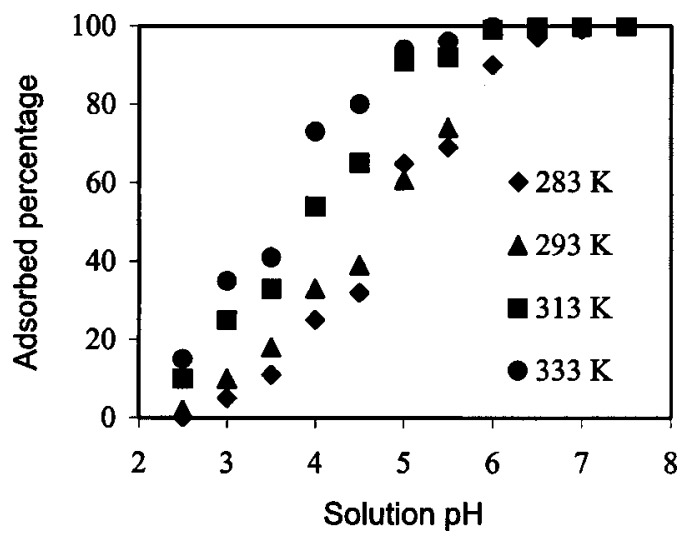

Fig. 1. pH-adsorption edges of lead ions onto goethite-coated medium under $\mathrm{Pb}_{(t)}=1 \times 10^{-4} \mathrm{M}$ at 283, 293, 313, and $333 \mathrm{~K}$ respectively

\section{Results and Discussion}

\section{Adsorption Data}

Fig. 1 shows the $\mathrm{pH}$-adsorption edges of lead ions onto goethitecoated medium under various temperatures. Adsorption percentages of lead are highly independent on temperature, and the $\mathrm{pH}$ adsorption edges shift to lower $\mathrm{pH}$ at higher temperature. Adsorption capacity of lead on goethite-coated medium increased with increasing temperature from 283 to $333 \mathrm{~K}$. Thus, it was indicated that the adsorption system should be an endothermic reaction. The results are in agreement with those of Rodda et al. (1993), Angove et al. (1999), Baker and Khalili (2004), and Martins et al. (2004), who reported that the adsorption reactions for many divalent ions are endothermic. The equilibrium constants for such reactions increase with increasing temperature, i.e., the reaction products (the adsorbed species) are favored at higher temperatures. At higher temperature, Rodda et al. (1993) and Angove et al. (1999) observed that the surface charge density of adsorbent surface decreased at a given $\mathrm{pH}$, and the hydrolysis of cations proceeded to a greater extent. Thus, an increase in temperature reduce the electrostatic repulsion between the adsorbent surface and adsorbing species, allowing adsorption to occur more readily.

\section{Adsorption Data Simulation}

A cation exchange model is used to simulate the adsorption reaction between goethite-coated medium and lead ions. This model considers the process of $A$ and $B$ cations exchange between the surface of goethite-coated medium and bulk solution. It is described as following equation

$$
\text { Surface } \| A_{e}+\frac{1}{b} B_{s}^{+b} \leftrightarrow \frac{1}{a} A_{s}^{+a}+\text { Surface } \| B_{e}
$$

where $a$ and $b=$ ionic charges, and subscrips $e$ and $s=$ exchangeable cations for solid surface and bulk solution, respectively. When the equilibrium is established, thermodynamic equilibrium constant $\left(K^{0}\right)$ can be written as 


$$
K^{0}=\frac{\left\{A_{s}^{+a}\right\}^{1 / a}\left\{B_{e}\right\}}{\left\{A_{e}\right\}\left\{B_{s}^{+b}\right\}^{1 / b}}
$$

When a suitable standard state is chosen it is assumed that both phases behave as an ideal solution in all concentrations, the previous equation can be rewritten as

$$
\frac{\left[B_{e}\right]}{\left[A_{e}\right]}=K \frac{\left[B_{s}^{+b}\right]^{1 / b}}{\left[A_{s}^{+a}\right]^{1 / a}}
$$

This equation is an ideal form of the Gapon equation, and it was used to describe the process of cation exchange in practice (Hillel 1980).

Assuming that the solid surface negative charge is independent of the solution $\mathrm{pH}$, surface cation concentration of bication exchange system can be written as follows:

$$
\left[A_{e}\right]=\frac{C E C-b\left[B_{e}\right]}{a}
$$

where $C E C=$ total amount of negative charge on the solid surface that can adsorb cations. Eq. (4) is substituted into Eq. (3), and $\left[B_{e}\right]$ can be written as

$$
\left[B_{e}\right]=\frac{C E C(K)\left[B_{s}^{+b}\right]^{1 / b}}{a\left[A_{s}^{+a}\right]^{1 / a}+K b\left[B_{s}^{+b}\right]^{1 / b}}
$$

If the activity of $A^{+a}$ in bulk solution always maintain as unity $\left(\left\{A_{s}^{+a}\right\}=1\right)$ and both ion charges are equal to 1 , i.e., $a=b=1$, Eq. (5) becomes a Langmuir adsorption equation:

$$
\left[B_{e}\right]=\frac{C E C(K)\left[B_{s}^{+b}\right]}{1+K\left[B_{s}^{+b}\right]}
$$

At equilibrium, the net change of free energy of system is zero, then:

$$
\Delta G^{\circ}=-R T \ln K \Rightarrow K=e^{-\Delta G^{\circ} / R T}
$$

According to the definition of Gibbs free energy, equilibrium constant $(K)$ can be written as Eq. (8) (Adamson 1982). Where $\Delta S^{\circ}$ and $\Delta H^{\circ}$ are the net entropy and enthalpy of ion exchange, respectively,

$$
K=e^{\Delta S^{\circ} / R} e^{-\Delta H^{\circ} / R T}
$$

If we assume that, over a limited temperature range, $\Delta S^{\circ}$ and $\Delta H^{\circ}$ are independent of temperature. The equilibrium concentration of exchanged cation on solid surface can be written as a function of temperature and ion concentrations in bulk solution by combining Eqs. (5) and (8).

$$
\left[B_{e}\right]=\frac{C E C\left(e^{\Delta S^{\circ} / R}\right)\left[B_{s}^{+b}\right]^{1 / b}}{b\left[B_{s}^{+b}\right]^{1 / b} e^{\Delta S^{\circ} / R}+a\left[A_{s}^{+a}\right]^{1 / a} e^{\Delta H^{\circ} / R T}}
$$

The structures of surface complex between the functional groups on goethite-coated medium surface and lead ions have been proposed. From the measured release of between one and two protons per lead ion adsorbed, that mono- (10) or binuclear (11) complexes may form (Schwertmann and Taylor 1989):

$$
\begin{gathered}
\equiv \mathrm{FeO} \cdot \mathrm{O}^{-} \mathrm{H}^{+}+\mathrm{Pb}^{+2} \leftrightarrow \mathrm{FeO} \cdot \mathrm{O}^{-} \mathrm{Pb}^{+2}+\mathrm{H}^{+} \\
\equiv\left(\mathrm{FeO} \cdot \mathrm{O}^{-} \mathrm{H}^{+}\right)_{2}+\mathrm{Pb}^{+2} \leftrightarrow\left(\mathrm{FeO} \cdot \mathrm{O}^{-}\right)_{2} \mathrm{~Pb}^{+2}+2 \mathrm{H}^{+}
\end{gathered}
$$

In this study, the cation exchange process is written as follows:

$$
\equiv \mathrm{FeO} \cdot \mathrm{O}^{-} \mathrm{H}^{+}+\frac{1}{n} \mathrm{~Pb}^{+n} \leftrightarrow \mathrm{FeO} \cdot \mathrm{O}^{-} \mathrm{Pb}_{1 / n}^{+n}+\mathrm{H}^{+}
$$

where $n=$ apparent or effective charge of $\mathrm{Pb}^{+2}$ for exchange. The value of $n$ should be between 1 and 2 that depends on the ratio of two possible mechanisms for $\mathrm{Pb}^{+2}$ adsorbed onto goethite-coated medium. The specific form of Eq. (9) for $\mathrm{Pb}^{+2}$ adsorbed onto goethite-coated medium can be written as follows:

$$
\left[\mathrm{Pb}_{e}\right]=\frac{C E C\left(e^{\Delta S^{\circ} / R}\right)\left[\mathrm{Pb}^{+n}\right]^{1 / n}}{\left[\mathrm{H}^{+}\right] e^{\Delta H^{\circ} / R T}+n\left[\mathrm{~Pb}^{+n}\right]^{1 / n} e^{\Delta S^{\circ} / R}}
$$

where $\left[\mathrm{Pb}_{e}\right]$ and $\left[\mathrm{Pb}^{+n}\right]$ are equilibrium concentrations on goethite-coated medium surface and in bulk solution, respectively, that can be measured from the adsorption experiments. The $C E C$, thermodynamic parameters, and apparent charge of lead ions in Eq. (13) can be evaluated via nonlinear regression analysis from the experimental data sets of $\left[\mathrm{Pb}_{e}\right],\left[\mathrm{Pb}^{+n}\right]$, temperature, and $\left[\mathrm{H}^{+}\right]$.

The values of thermodynamic parameters, apparent charge of lead ions for exchange and $C E C$ on goethite-coated medium were evaluated by nonlinear regression analysis from 121 data sets of the adsorption experiments. The solution $\mathrm{pH}$ and temperature ranged from 2.5 to 7.5 and from 283 to $333 \mathrm{~K}$, respectively. Under the constraints of $2 \geqslant n \geqslant 1$ and $C E C>0$, the best fitting results of Eq. (13) are listed in Table 1. The ANOVA of regression inspects the fitness of model. High correlation coefficient $\left(r^{2}=0.91\right)$ and extreme low $p$ value $\left(7.02 \times 10^{-82}\right)$ indicates that the variance of dependent variable, $\left[\mathrm{Pb}_{e}\right]$, could be firmly explained by independent variables $\left(\left[\mathrm{Pb}^{+n}\right]\right.$, temperature, and $\left.\left[\mathrm{H}^{+}\right]\right)$. The net entropy $\left(\Delta S^{\circ}\right)$ and enthalpy $\left(\Delta H^{\circ}\right)$ of cation exchange are $25.94 \mathrm{cal} / \mathrm{mol} \mathrm{K}$ and $10,816 \mathrm{cal} / \mathrm{mol}$, respectively. Fig. 2 shows the comparison between experimental and simulation data under various temperatures, solution $\mathrm{pH}$, and lead concentration. The experimental data are highly significant by Eq. (13) regression. On the other hand, the equilibrium concentration of $\mathrm{Pb}$ in bulk solution was less than $10^{-3} \mathrm{~mol} / \mathrm{L}$ and mole fraction of $\mathrm{Pb}$ adsorbed on goethite-coated medium was no more than 0.07 . Further, no electrolytes were added to maintain ionic strength in solution except adjusting the solution $\mathrm{pH}$ by $\mathrm{HNO}_{3}$. Therefore, experimental condition could be considered as nearly diluted in practice. The calculated $\Delta G^{\circ}$ is $3,082 \mathrm{cal} / \mathrm{mol}$ at $298 \mathrm{~K}$. Comparing with binary cations exchange process on soils or soil components (Sparks 1995), the $\Delta H^{\circ}$ and $\Delta S^{\circ}$ of $\mathrm{Pb}-\mathrm{H}$ cations exchange process on goethite-coated medium in this study is quite similar to the other divalent-monovalent ions pair.

Langmuir adsorption isotherm was employed to describe the adsorption phenomena of metal ions onto iron oxide. Although the regression value of $r^{2}$ is always high, and it is enough to establish the significance of model. However, the model still fails to explain the endothermic process why metal cations adsorbed on the solid surface were more free than in the bulk solution. Primary considerations of Langmuir adsorption model do not in-

Table 1. Estimated Values of Parameters in the $95 \%$ Confidence Intervals

\begin{tabular}{lccc}
\hline Parameter & $\begin{array}{c}\text { Estimated } \\
\text { value }\end{array}$ & $\begin{array}{c}\text { Standard } \\
\text { error }\end{array}$ & $\begin{array}{c}\text { Confidence } \\
\text { interval }(95 \%)\end{array}$ \\
\hline$C E C(\mathrm{eq} / \mathrm{kg})$ & 0.912 & 0.067 & $0.780-1.045$ \\
$n$ & 1.265 & 0.083 & $1.100-1.430$ \\
$\Delta H^{0}(\mathrm{cal} / \mathrm{mol})$ & 10,816 & 703 & $9424-12208$ \\
$\Delta S^{0}(\mathrm{cal} / \mathrm{mol} \mathrm{K})$ & 25.94 & 2.60 & $20.89-31.08$ \\
\hline
\end{tabular}




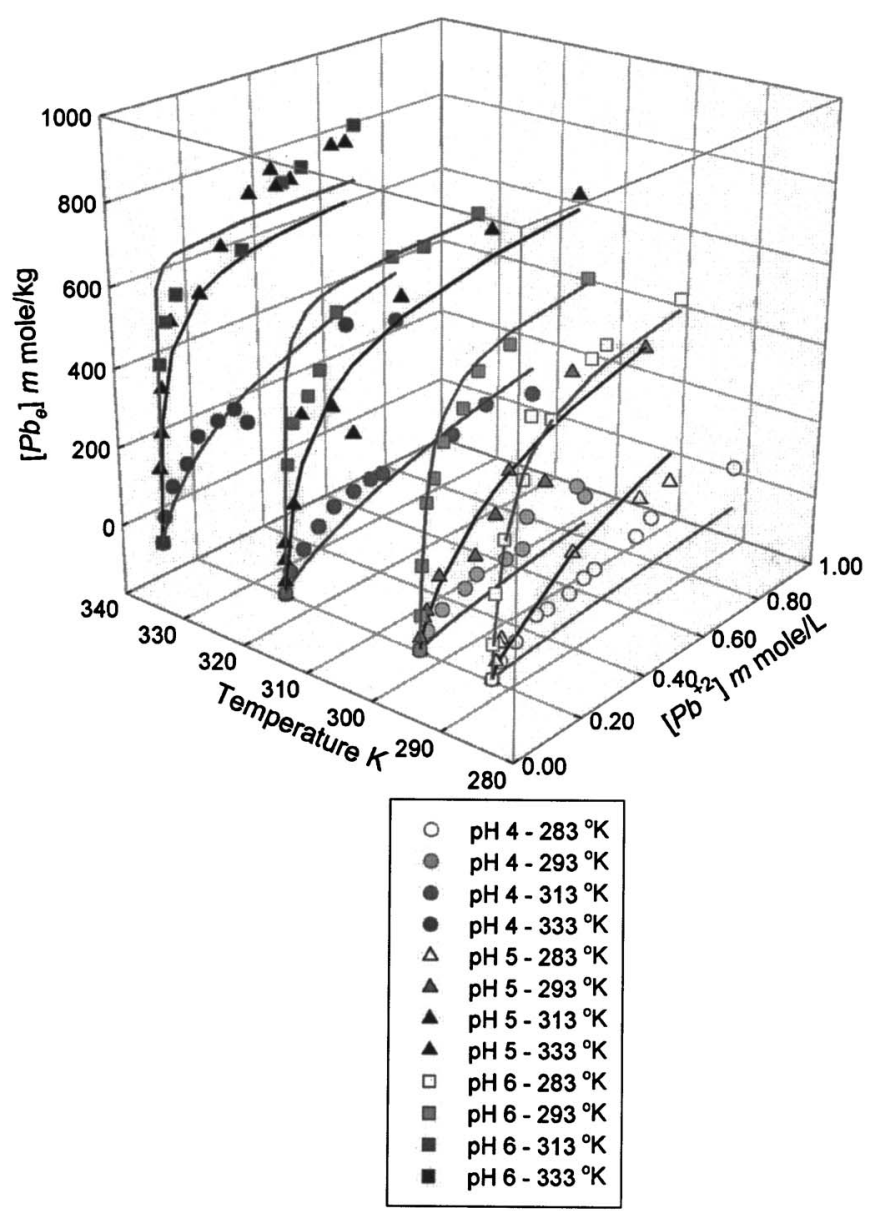

Fig. 2. Comparison between experimental and simulation data under various temperatures, solution $\mathrm{pH}$, and lead concentrations, respectively

clude the counter part of adsorbate, therefore it is generally limited to the nonelectrolyte solute only. When apply this to the ion exchange process, the Langmuir model must be limited to monovalent-monovalent ion pairs only, and the counter ion must always be maintained as unit activity, just as mentioned in Eq. (6). Thus, the effect of solution $\mathrm{pH}$ could not be considered simultaneous. In general, another independent potential titration experiment must be conducted to measure the release of proton and the effect of solution $\mathrm{pH}$. Obviously, the cation exchange model of lead ions adsorbed onto goethite-coated medium was more reasonable than that of Langmuir adsorption isotherm. Not only the effects of solution concentration, temperature, and $\mathrm{pH}$ could be taken into consideration at same time. It also explains the driving force of adsorption process. In this study, the adsorption process is an endothermic reaction, the main driving force of reaction must come from the increase of entropy.

In order to illustrate the interaction between lead ions and iron-coated medium, EDAX chemical analysis was used for characterizing the lead adsorption sites on goethite-coated medium. The spectrum of eluted goethite-coated medium by using elemental microprobe analysis of EDAX is illustrated in Fig. 3. Nonspecific adsorption of ions is unable to exist on the surface of goethite-coated medium through a complete elution process (Hsia et al. 1994; Lai et al. 2000a, b, 2002). However, lead becomes the principal element of the solid sample except $\mathrm{Fe}, \mathrm{Si}$, and trace $\mathrm{O}, \mathrm{S}$ signals are detected in this spectrum. This was due to the fact that

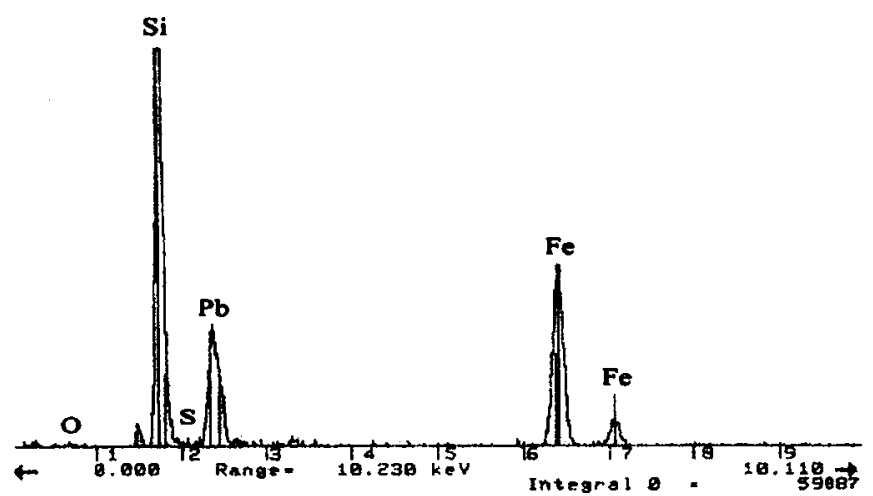

Fig. 3. EDAX spectrum of goethite-coated medium under adsorbed lead ions at $\mathrm{Pb}_{(t)}=1 \times 10^{-4} \mathrm{M}$ and $\mathrm{pH}=5.0$

lead ions were chemisorbed on the surface of goethite-coated sand. The EDAX analysis therefore provides the direct evidence for specific adsorption of lead ions on the surface of goethitecoated medium. The results are consistent with those reported earlier that metal ions such as arsenate, cadmium, and copper were chemisorbed onto various crystalline phases of iron oxides (Hsia et al. 1994; Lai et al. 2000a, b, 2002).

\section{Conclusions}

The solution temperature and $\mathrm{pH}$ were shown to be a significant influence for lead ion adsorption onto goethite-coated medium, and the final lead adsorption capacity increased with increasing temperature. Lead became the principal element of the solid sample except $\mathrm{Fe}, \mathrm{Si}$, and $\mathrm{O}$, this was due to the fact that lead ions were chemisorbed on the surface of an iron-coated medium. The EDAX analysis provided the direct evidence for specific adsorption of lead ions on the surface of an iron-coated medium.

The adsorption reaction between lead ions and a goethitecoated medium was an endothermic process, the main driving force of reaction came from the increase of entropy. The cation exchange model was sufficient to simulate the adsorption reaction between goethite-coated medium and lead ions. High correlation coefficient and low $p$ values of ANOVA regression indicated that the adsorption capacity of goethite-coated medium could be firmly explained by independent variables, such as $\left[\mathrm{Pb}^{+n}\right]$, temperature and $\left[\mathrm{H}^{+}\right]$. The net entropy $\left(\Delta S^{\circ}\right)$ and enthalpy $\left(\Delta H^{\circ}\right)$ of cation exchange were $25.94 \mathrm{cal} / \mathrm{mol} \mathrm{K}$ and $10,816 \mathrm{cal} / \mathrm{mol}$, respectively. The $\Delta H^{\circ}$ and $\Delta S^{\circ}$ of $\mathrm{Pb}-\mathrm{H}$ cations exchange process on goethite-coated medium in this study was quite similar to the divalent-monovalent ions pair.

\section{Acknowledgments}

The writers express their gratitude to the National Science Council of the Republic of China (Contract Nos. NSC 93-2211E-242-009 and NSC 94-2211-E-242-007) for its financial support.

\section{References}

Adamson, W. (1982). Physical chemistry of surfaces, 4th Ed., Wiley, New York, 371.

Angove, M. J., Well, J. D., and Johnson, B. B. (1999). "The influence of 
temperature on the adsorption of cadmium and cobalt on goethite." J. Colloid Interface Sci., 211, 218-290.

Baes, A. U., Okuda, T., Nishijima, W., Shoto, E., and Okada, M. (1997). "Adsorption and ion exchange of some groundwater anion contaminants in the amine modified coconut coir." Water Sci. Technol., 35(7), 89-96.

Baker, H., and Khalili, F. (2004). "Analysis of the removal of lead (II) from aqueous solutions by adsorption onto insolubilized humic acid: Temperature and $\mathrm{pH}$ dependence." Anal. Chim. Acta, 516, 179-186.

Benjamin, M. M., and Leckie, J. O. (1981). "Multiple site adsorption of $\mathrm{Cd}, \mathrm{Cu}, \mathrm{Zn}$ and $\mathrm{Pb}$ on amorphous iron oxyhydroxide." J. Colloid Interface Sci., 79, 209-215.

Benjamin, M. M., Sletten, R. S., Bailey, R. P., and Bennett, T. (1996), "Sorption and filtration of metals using iron-oxide-coated sand." Water Res. 30(11), 2609-2619.

Edwards, M., and Benjamin, M. M. (1989). "Adsorptive filtration using coated sand: A new approach for treatment of metal-bearing wastes." J. Water Pollut. Control Fed., 61(9), 1523-1533.

Hillel, D. (1980). Fundamentals of soil physics, Academic, New York, 83.

Hsia, T. H., Lo, S. L., Lin, C. F., and Lee, D. Y. (1994). "Characterization of arsenate adsorption on hydrous iron oxide using chemical and physical methods." Colloids Surf., A, 85, 1-7.

Joshi, A., and Chaudhuri, M. (1996). "Removal of arsenic from ground water by iron oxide-coated sand." J. Environ. Eng., 122(8), 769-771.

Lai, C. H., and Chen, C. Y. (2001). "Removal of metal ions and humic acid from water by iron-coated filter media." Chemosphere, 41, $1177-1184$.

Lai, C. H., Chen, C. Y., Shih, P. H., and Hsia, T. H., (2000a). "Competitive adsorption of copper and lead ions on an iron-coated sand from water." Water Sci. Technol., 42(3-4), 149-154.

Lai, C. H., Chen, C. Y., Wei, B. L., and Yeh, S. H. (2002). "Cadmium adsorption on the goethite-coated sand in the presence of humic acid." Water Res., 36, 4943-4950.

Lai, C. H., Lo, S. L., and Chiang, H. L., (2000b). "Adsorption/desorption properties of copper ions on the surface of the iron-coated sand using BET and EDAX analyses." Chemosphere, 41, 1249-1255.

Martins, R. J. E., Pardob, R., and Boaventurab, R. A. R. (2004). "Cadmium(II) and zinc(II) adsorption by the aquatic moss Fontinalis antipyretica: Effect of temperature, $\mathrm{pH}$ and water hardness." Water Res., 38, 693-699.

McKenzie, R. M. (1980). "The adsorption of lead and other heavy metals on oxides of manganese and iron." J. Soil Res., 18, 61-73.

Rodda, D. P., Jonson, B. B., and Well, J. D. (1993). "The effect of temperature and $\mathrm{pH}$ on the adsorption of copper, lead, and zinc onto goethite." J. Colloid Interface Sci., 161, 57-62.

Schwertmann, U., and Taylor, R. M. (1989). "Iron oxides." Minerals in soil environments, J. B. Dixon and S. B. Weed, eds., 2nd Ed., Soil Science Society America Journal, Madison, Wis., 379-428.

Sharma, Y. C. (2001). "Effect of temperature on interfacial adsorption of Cr(VI) on wollastonite.” J. Colloid Interface Sci., 233, 265-270.

Singh, D. B., Rupainwar, D. C., Prasad, G., and Jayaprakas, K. C. (1998). "Study on the Cd removal from water by adsorption." J. Hazard. Mater., 60, 29-40.

Singh, D. K., Tiwari, D. P., and Saksena, D. N. (1993). "Removal of lead from aqueous solutions by chemically treated used tea leaves." Indian J. Environ., 35(3), 169-177.

Sparks, D. L. (1995). Environmental soil chemistry, Academic, New York, 156. 